\title{
Clinical indications for image-guided interventional procedures in the musculoskeletal system: a Delphi-based consensus paper from the European Society of Musculoskeletal Radiology (ESSR) - part VI, foot and ankle
}

\author{
Luca Maria Sconfienza $^{1,2}$ (D) Miraude Adriaensen ${ }^{3}$ • Domenico Albano ${ }^{1,4}$ • Andrea Alcala-Galiano ${ }^{5}$ Georgina Allen $^{6,7}$. \\ Maria Pilar Aparisi Gómez ${ }^{8,9}$. Giacomo Aringhieri ${ }^{10}$. Alberto Bazzocchi ${ }^{11}$ • lan Beggs ${ }^{12}$. Vito Chianca $^{13,14}$. \\ Angelo Corazza ${ }^{1}$ - Danoob Dalili ${ }^{15}$. Miriam De Dea ${ }^{16}$. Jose Luis del Cura ${ }^{17}$. Francesco Di Pietto $^{18}$. \\ Elena Drakonaki $^{19}$ - Fernando Facal de Castro ${ }^{20}$. Dimitrios Filippiadis ${ }^{21}$. Salvatore Gitto ${ }^{22}$. Andrew J Grainger ${ }^{23}$. \\ Simon Greenwood ${ }^{24}$ - Harun Gupta ${ }^{25}$. Amanda Isaac ${ }^{15,26}$. Slavcho Ivanoski ${ }^{27,28}$ - Monica Khanna ${ }^{29}$.

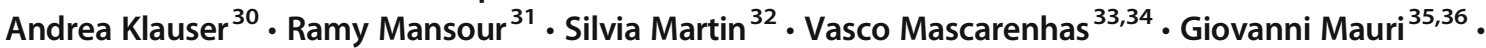 \\ Catherine McCarthy ${ }^{37} \cdot$ David McKean $^{38} \cdot$ Eugene McNally $^{37} \cdot$ Kalliopi Melaki $^{39} \cdot$ Carmelo Messina $^{1} \cdot$ Rebeca Mirón \\ Mombiela $^{40}$ - Ricardo Moutinho ${ }^{33,41}$. Cyprian Olchowy ${ }^{42}$ - Davide Orlandi ${ }^{43}$ - Raquel Prada González ${ }^{44}$. \\ Mahesh Prakash ${ }^{45}$ - Magdalena Posadzy ${ }^{46}$. Saulius Rutkauskas ${ }^{47}$ - Žiga Snoj ${ }^{48,49}$ • Alberto Stefano Tagliafico ${ }^{50,51}$.

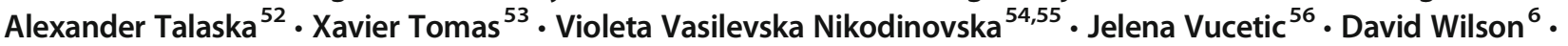 \\ Federico Zaottini ${ }^{51}$ - Marcello Zappia ${ }^{57,58}$ - Marina Obradov ${ }^{59}$
}

Received: 27 March 2021 / Accepted: 7 June 2021 / Published online: 25 August 2021

(C) The Author(s) 2021

\section{Abstract}

Objectives Clarity regarding accuracy and effectiveness for interventional procedures around the foot and ankle is lacking. Consequently, a board of 53 members of the Ultrasound and Interventional Subcommittees of the European Society of Musculoskeletal Radiology (ESSR) reviewed the published literature to evaluate the evidence on image-guided musculoskeletal interventional procedures around this anatomical region.

Methods We report the results of a Delphi-based consensus of 53 experts from the European Society of Musculoskeletal Radiology who reviewed the published literature for evidence on image-guided interventional procedures offered around foot and ankle in order to derive their clinical indications. Experts drafted a list of statements and graded them according to the Oxford Centre for evidence-based medicine levels of evidence. Consensus was considered strong when $>95 \%$ of experts agreed with the statement or broad when $>80 \%$ but $<95 \%$ agreed. The results of the Delphi-based consensus were used to write the paper that was shared with all panel members for final approval.

Results A list of 16 evidence-based statements on clinical indications for image-guided musculoskeletal interventional procedures in the foot and ankle were drafted after a literature review. The highest level of evidence was reported for four statements, all receiving $100 \%$ agreement.

Conclusion According to this consensus, image-guided interventions should not be considered a first-level approach for treating Achilles tendinopathy, while ultrasonography guidance is strongly recommended to improve the efficacy of interventional procedures for plantar fasciitis and Morton's neuroma, particularly using platelet-rich plasma and corticosteroids, respectively.

Luca Maria Sconfienza

io@lucasconfienza.it

Extended author information available on the last page of the article 


\section{Key Points}

- The expert panel of the ESSR listed 16 evidence-based statements on clinical indications of image-guided musculoskeletal interventional procedures in the foot and ankle.

- Strong consensus was obtained for all statements.

- The highest level of evidence was reached by four statements concerning the effectiveness of US-guided injections of corticosteroid for Morton's neuroma and PRP for plantar fasciitis.

Keywords Interventional radiology $\cdot$ Ultrasonograph $\cdot$ Ankle $\cdot$ Foot $\cdot$ Achilles tendon

\author{
Abbreviations \\ AT Achilles degenerative tendinopathy \\ ESSR European Society of Musculoskeletal Radiology \\ HA Hyaluronic acid \\ PF Plantar fasciitis \\ PRP Platelet-rich plasma \\ RCT Randomized controlled trials \\ US Ultrasonography
}

\section{Introduction}

Musculoskeletal interventional procedures are routinely performed around the foot and ankle, including injections and variable interventions on tendons, bursae, plantar fascia, nerves, and joints [1-3]. Some of them are superficial and can be easily approached using palpation, but others generally require imaging, specifically ultrasonography (US), to guide the procedure and to accurately deliver the medications [4-6]. Indeed, foot and ankle musculoskeletal structures can be very small and located close to neurovascular bundles that can be damaged during the procedures [7-9]. No clear guidelines have been produced concerning the use of imaging guidance for musculoskeletal interventional procedures around the foot and ankle. Clarity is needed regarding the accuracy and effectiveness of these interventions. These procedures are widely adopted by different physicians, but there is no consensus on which image-guided procedures should be considered first, particularly when involving relatively novel approaches, including hyaluronic acid (HA), regenerative medications like platelet-rich plasma (PRP), or ablation (e.g., radiofrequency and cryoablation of Morton's neuroma) [10-12]. The Ultrasound and the Interventional Subcommittees of the European Society of Musculoskeletal Radiology (ESSR) carried out a collaborative task, with the support of its Research Committee, to analyze the published literature on imageguided musculoskeletal interventional procedures in the lower limb to establish clinical indications (upcoming publication in Eur Radiol). We report the evidence-based statements for clinical indications of image-guided musculoskeletal interventional procedures around the foot and ankle listed by an expert board of the ESSR after a Delphi method performed a review of current literature.

\section{Materials and methods}

Institutional Review Board approval was not needed as no patients were directly involved. This paper arises from the review of published evidence on image-guided interventional musculoskeletal procedures around the foot and ankle. Similar to previous ESSR consensus papers [13-16], a literature-based Delphi method of review was used. It includes multiple rounds of evaluation of the existing literature to assess the opinion of a panel of experts on this topic. A list of statements were discussed and drafted to reach a final shared agreement [17]. We used the AGREE II tool to guarantee the quality of the working flow [18]. The different steps of the Delphi method are thoroughly explained and reported as supplementary material.

\section{Results}

1. Image-guided injections are safe and feasible to treat Achilles degenerative tendinopathy (AT), but there is insufficient evidence from randomized controlled trials (RCT) to support them over conservative therapies.

Level of evidence: 1

Agree, $n=53$; disagree, $n=0$; abstain, $n=0$. Agreement $=$ $100 \%$

Both the Cochrane Review of 2015 [19] and Maffulli's systematic review [20] concluded that there is insufficient evidence from RCTs to support the use of injection therapies. The evidence has not changed since then. Previous metaanalyses of RCTs demonstrated no superiority of US-guided PRP injections over placebo [11,21-25]. Notably, PRP injections and dry needling have similar short-term results with weekly injections of PRP or dry needling for 3 weeks having shown no clinical difference at 3 or 6 months [26]. A systematic review reported local US-guided corticosteroid injections have no therapeutic role to treat AT [27] and subcutaneous fat atrophy and tendon damage may occur [28]. A systematic review of many high-quality RCTs showed corticosteroid injections reduced pain in the short term compared with other interventions, but this effect was reversed in the intermediate and long term [29]. There is controversial evidence that bone 
marrow aspirate and stem cells help in the treatment of AT, with few studies suggesting a potential short-term clinical improvement, with no role for imaging to predict or assess the response [30,31]. A meta-analysis reported that prolotherapy may be safe and effective for AT [32]. However, long-term studies and RCTs are still missing and one RCT found no clinical difference between prolotherapy and the control group. No significant pain variation was found between polidocanol and lidocaine injection for AT [33].

High-volume injections seem to be effective at treating AT, but confounding factors such as corticosteroid, aprotinin, dry needling, or eccentric exercise prevent assessment of this method alone [34, 35].

2. Image-guided anesthetic-corticosteroid injections into the anterior and posterior tibial tendon sheaths are safe and may provide effective diagnosis and treatment in patients with anterior and posterior tibial tendon tenosynovitis.

Level of evidence: 3

Agree, $n=53$; disagree, $n=0$; abstain, $n=0$. Agreement $=$ $100 \%$

Several studies reported complete or near-complete prolonged symptom relief after anesthetic-corticosteroid injections for tenosynovitis unresponsive to conservative management [36-40]. A study [39] using US guidance successfully demonstrated excellent improvement of the tendon sheath effusion and synovial hypertrophy around the anterior and posterior tibial tendon 4 weeks after injection.

\section{US-guided corticosteroid injections are more effective} than palpation-guided injections to treat plantar fasciitis (PF) providing significant short-term pain relief, particularly when combined with strength training and stretching.

Level of evidence: 2

Agree, $n=53$; disagree, $n=0$; abstain, $n=0$. Agreement $=$ $100 \%$

A meta-analysis included 5 RCTs with 149 patients and concluded that US-guided injections were superior with regard to VAS, tenderness threshold, response rate, plantar fascia thickness, and hypoechogenicity. There was no difference in heel pad thickness and heel tenderness index [41]. A comparative trial concluded that device-assisted US-guided injection for treating $\mathrm{PF}$ was superior to palpation-guided injection [42]. US-guided corticosteroid injections are associated with lower heel pain recurrence when compared to palpation guidance. Comparative trials of US-guided corticosteroid injections versus placebo reported greater pain relief in the corticosteroid arm lasting up to
12 weeks [43]. Case series in the literature report efficacy of corticosteroid injections for $\mathrm{PF}$ with objective measurement of the therapeutic effect on proximal PF without significant deterioration of heel pad mechanical properties [44-47]. Combining corticosteroid injections with strength training and stretching is superior both in the short- and in the long term and can be recommended as a first-line treatment in patients with $\mathrm{PF}$ [48].

4. US-guided PRP injections for PF are safe and provide significant pain relief in chronic PF, with better clinical outcome at mid- and long-term follow-up if compared with corticosteroid injections.

Level of evidence: 1

Agree, $n=53$; disagree, $n=0$; abstain, $n=0$. Agreement $=$ $100 \%$

Four meta-analysis studies having compared US-guided PRP and corticosteroid support the use of PRP instead of corticosteroids, highlighting the favorable and long-lasting clinical outcomes in patients with chronic PF [10, 49-51].

5. The effectiveness of US-guided injections with ozone, hyaluronic acid, or botulinum toxin type A has not still sufficiently proven to be recommended for $\mathrm{PF}$.

Level of evidence: 3

Agree, $n=53$; disagree, $n=0$; abstain, $n=0$. Agreement $=$ $100 \%$

Limited number of outcome-based investigation studies reported the effectiveness of those methods to treat painful PF without inducing fat pad atrophy [52-54]. Most studies are case series or trials comparing different doses of the same substance [54], but no comparative studies are available.

6. US and fluoroscopy guidance improves the accuracy of joint injections in the foot and ankle although these procedures can be safely performed with palpation alone.

Level of evidence: 4

Agree, $n=53$; disagree, $n=0$; abstain, $n=0$. Agreement $=$ $100 \%$

Intra-articular injections of the foot and ankle using palpation and US were conducted on a cadaver model and were both $100 \%$ accurate [55]. The risk of extravasation into the ankle or peroneal tendon sheath is higher when injections are unguided [56]. When injections are used for diagnostic purposes and surgical decision-making, especially in abnormal joints, imaging guidance is useful. The use of US or fluoroscopy significantly improved the accuracy of injections into the tarsometatarsal joints [55]. A cadaveric study on talonavicular 
joint injection accuracy showed that the needle was correctly positioned in all US-guided injections, while it was misplaced in all cases of blind injections [57]. In juvenile idiopathic arthritis patients with ankle synovitis, image-guided intra-articular corticosteroid injections resulted in longer remission time when compared with palpation guidance [58].

7. Image-guided corticosteroid injections for midfoot joint osteoarthritis might provide short-term improvement, but further studies are warranted to support their clinical use.

Level of evidence: 4

Agree, $n=53$; disagree, $n=0$; abstain, $n=0$. Agreement $=$ $100 \%$

Two uncontrolled studies of intra-articular corticosteroid injections for midfoot osteoarthritis led to short-term improvement with poor long-term outcome [59, 60]. Symptom improvement reported at 3-4 months was generally not sustained at 12 months $[59,60]$. Larger prospective RCTs are needed.

\section{PRP and prolotherapy are safe methods to treat} osteochondral lesions of the talus with promising results, but evidence on efficacy is limited.

Level of evidence 4

Agree, $n=53$; disagree, $n=0$; abstain, $n=0$. Agreement $=$ $100 \%$

PRP and prolotherapy are shown to be safe methods to treat talus osteochondral lesions and might be considered treatment options for younger patients and for patients with early stage and small lesions, as reported in a single retrospective cohort study including 49 patients ( $n=27$ prolotherapy, $n=22$ PRP) [61]. Prolotherapy is cheaper and less invasive [61]. However, further studies are still required.

9. Intraarticular foot and ankle anesthetic injections performed under imaging guidance offers precise information about pain source.

Level of evidence: 4

Agree, $n=53$; disagree, $n=0$; abstain, $n=0$. Agreement $=$ $100 \%$

Fluoroscopically guided foot and ankle joint anesthetic injections aid diagnosis and have a potential for targeted therapy when combined with corticosteroids. Large and small joints in the foot and ankle are readily accessed $[62,63]$. Anesthetic response for surgical planning is controversial [64, 65], as many foot joints are interconnected, with a potential confounding effect, but when correlated with magnetic resonance or computed tomography arthrography, they may help confirm the diagnosis $[63,66]$.

10. US-guided tarsal tunnel decompression is a feasible procedure in cadavers, but clinical value is unknown.

Level of evidence: 4

Agree, $n=52$; disagree, $n=1$; abstain, $n=0$. Agreement $=$ $98 \%$

US-guided tarsal tunnel decompression associated with flexor retinaculum release was feasible in a cadaveric study without any vascular or neurological damage [67]. However, no data is available about in-vivo feasibility and efficacy.

11. US-guided injections of bursae around the foot are technically feasible, but clinical value is unknown.

Level of evidence: 5

Agree, $n=53$; disagree, $n=0$; abstain, $n=0$. Agreement $=$ $100 \%$

Foot bursae aspiration and injection could be performed in a wide series of rheumatologic and degenerative conditions [68], but evidence about the interventional approach for foot bursitis is poor. There is minor evidence for intermetatarsal bursa US-guided corticosteroid injection feasibility and its therapeutic role in Morton's syndrome [69].

\section{US-guided deep retrocalcaneal bursa injections are feasible.}

Level of evidence: 4

Agree, $n=53$; disagree, $n=0$; abstain, $n=0$. Agreement $=$ $100 \%$

Deep retrocalcaneal bursa injections are feasible and effective both under US [70] and fluoroscopy [71] guidance but there is more evidence for US guidance [72]. A direct comparison between the two methods is not available, and the evidence about injection indications is weak. Local US-guided corticosteroid injection of the retrocalcaneal bursa improves bursitis symptoms but risks Achilles tendon rupture [73].

13. US-guided corticosteroid injections are the most effective image-guided interventional procedure to improve pain in patients with Morton's neuroma, especially in the first 3 months.

Level of evidence: 1

Agree, $n=53$; disagree, $n=0$; abstain, $n=0$. Agreement $=$ $100 \%$ 
A systematic review identified eight different types of interventions for Morton's neuroma. The most frequent procedure was US-guided corticosteroid (7 studies) and sclerosing injections (7 studies). A meta-analysis of two RCTs conducted in the same study found that US-guided corticosteroid injections decreased pain more than controls. Other RCTs reported the efficacy of mobilization or extracorporeal shockwave therapy versus control. Treatment success was evaluated for extracorporeal shockwave therapy versus control and for corticosteroids versus footwear padding. Sclerosing and Botox injections, radiofrequency ablation, and cryoneurolysis had been investigated only by case studies with limited methodological quality [74]. Results from a patient-blinded trial [75] comparing US-guided injection of either corticosteroid-anesthetic or anesthetic alone demonstrated that the corticosteroid group had significantly better clinical improvement at 1 and 3 months. Controversial results have been reported by a double-blinded RCT [76] comparing three US-guided injections of either corticosteroidanesthetic or local anesthetic alone, showing no clinical differences between the groups at 3 and 6 months.

\section{US guidance improves the effectiveness of different interventional procedures for Morton's neuroma if compared to palpation guidance, particularly for corticosteroid injection.}

Level of evidence: 1

Agree, $n=53$; disagree, $n=0$; abstain, $n=0$. Agreement $=$ $100 \%$

When compared to palpation guidance, US was proven to increase the effectiveness of interventional procedures in patients with Morton's neuroma. A systematic review [77] reported that US guidance may produce better short- and long-term pain relief after corticosteroid injection and can reduce surgical referral rate, and need for additional procedures after ethanol injection. An RCT [78] concluded that US-guided injection of Morton's neuroma provides significant improvement at 45, 60, and 90 days compared with palpation-guided injections. Multiple studies reported the use of US guidance using different types of intervention with satisfactory results: corticosteroids [69, 75, 76, 79-81], alcohol [82-88], radiofrequency [89-91], and hyaluronic acid [92]. A case study concluded that the injection of Morton's neuroma was better tolerated via a dorsal approach and the preliminary use of local anesthetic did not confer any benefit [93]. There is conflicting evidence about the relationship between Morton's neuroma size and efficacy of US-guided anesthetic and/or corticosteroid injection. A casecontrol study [94] concludes that size and age appear to be predictors for further treatment within 2 years from corticosteroid injection. Another case study [95] reported that the effectiveness of corticosteroid injection appears to be more significant and long-lasting for lesions $<5 \mathrm{~mm}$. However, results from a patient-blinded RCT [75] comparing corticosteroid-anesthetic versus anesthetic alone reported that the neuroma size did not significantly influence the treatment effect.

15. US-guided ethanol injection of Morton's neuroma is relatively safe and well-tolerated, but further investigations are required to clearly demonstrate its clinical value prior to supporting this procedure.

Level of evidence: 2

Agree, $n=53$; disagree, $n=0$; abstain, $n=0$. Agreement $=$ $100 \%$

A systematic review [88] found that ethanol injections appear to be safe, although some papers report short-term side effects due to an inflammatory reaction. Ethanol concentration and US guidance versus unguided injections vary. Evidence suggests ethanol has a sclerosing histological effect on the interdigital nerve but all reviewed studies had methodological flaws causing bias and poor evidence. A level 3 [87] and multiple level 4 studies $[82,83,85,86,88]$ explored treatment with US-guided ethanol injection, with good tolerance and high success rate. A prospective case series [84] demonstrated that short-term benefits from ethanol injection exist with considerable morbidity and no long-term benefit. Pain and satisfaction scores showed significant deterioration after 5 years. Fluoroscopic and electroneurographic guidance gave a success rate (defined as free of pain in daily life) of more than $82 \%$ per single ethanol injection with no recurrence over 5 years [96].

\section{Image-guided thermal ablation of Morton's neuroma is safe with promising initial results and might reduce the need for surgery in the short term.}

Level of evidence: 4

Agree, $n=53$; disagree, $n=0$; abstain, $n=0$. Agreement $=$ $100 \%$

Case series reported the use of radiofrequency ablation as a safe and efficient potential treatment for Morton's neuroma $[90,91]$. A case series [89] reported successful symptom relief in $>85 \%$ of cases, and only $10 \%$ of patients needed surgery in the short term. Radiofrequency ablation has the disadvantage of being more expensive compared to corticosteroid injections. Neurolysis is a treatment used for chronic peripheral pain, with cryotherapy being recognized as a well-tolerated procedure among the different methods of nerve ablation. MR-guided Morton's neuroma cryoablation has been reported by Cazzato et al as a feasible and tolerated technique with initially promising results requiring further investigation [12]. Friedman and colleagues reported good clinical results from a retrospective study on 20 patients subjected to USguided cryoablation of Morton's neuroma [97]. 


\section{Discussion}

This panel listed 16 evidence-based statements on clinical indications of image-guided musculoskeletal interventional procedures in the foot and ankle, with strong consensus reached for all statements. The highest level of evidence was reached by four statements concerning the effectiveness of US-guided injections of corticosteroid for Morton's neuroma and PRP for PF, and also concerning the limited role of injection therapies in AT.

Despite the safety and efficacy of image-guided injections for AT, the superiority of these procedures over conservative therapies has not been proven, leading us to consider them a secondlevel approach for treating patients with AT (statement \#1).

Regarding PF, prospective RCTs demonstrated the added value of US guidance to improve the clinical outcome of interventional procedures over blinded injections (statement \#3). The highest level of evidence paper showed that USguided PRP injections have better and long-lasting effects than US-guided corticosteroid injections in patients with PF (statement \#4). In patients with Morton's neuroma, the highest level of evidence papers showed that US guidance improves the efficacy of several interventional procedures (statement \#14), particularly corticosteroid injections used to improve pain in the short-/mid-term (statement \#13). Although ethanol injections, radiofrequency, and cryoablation seem to be safe alternatives for treating Morton's neuroma, the clinical value of these interventions still needs further clarification (statements \#15 and \#16).

Anecdotal reports and small case series have shown the feasibility, safety, and effectiveness of image-guided injections of ankle/foot joints (statements \#6-9) and bursae (statements \#11-12), with too limited evidence to support these in routine clinical practice.

In conclusion, 16 statements about image-guided musculoskeletal interventional procedures around the foot and ankle have been produced by an expert panel of the ESSR. Imageguided interventions should not be considered a first-level approach for AT. US is strongly recommended as a guidance for interventions for PF and Morton's neuroma to improve the effectiveness of the procedures, particularly using PRP and corticosteroids, respectively.

Supplementary Information The online version contains supplementary material available at https://doi.org/10.1007/s00330-021-08125-z.

Acknowledgements All authors are members of the Ultrasound and/or Interventional Subcommittees of the European Society of Musculoskeletal Radiology (ESSR).

Funding Open access funding provided by Università degli Studi di Milano within the CRUI-CARE Agreement.

\section{Declarations}

Guarantor The scientific guarantor of this publication is Luca Maria Sconfienza, MD, PhD.

Conflict of interest The authors of this manuscript declare no relationships with any companies whose products or services may be related to the subject matter of the article.

Statistics and biometry No complex statistical methods were necessary for this paper.

Informed consent Written informed consent was not required for this study because no informed consent was needed as this paper does not involve patients.

Ethical approval Institutional Review Board approval was not required because this paper does not involve patients.

\section{Methodology}

- Multicentre study

Open Access This article is licensed under a Creative Commons Attribution 4.0 International License, which permits use, sharing, adaptation, distribution and reproduction in any medium or format, as long as you give appropriate credit to the original author(s) and the source, provide a link to the Creative Commons licence, and indicate if changes were made. The images or other third party material in this article are included in the article's Creative Commons licence, unless indicated otherwise in a credit line to the material. If material is not included in the article's Creative Commons licence and your intended use is not permitted by statutory regulation or exceeds the permitted use, you will need to obtain permission directly from the copyright holder. To view a copy of this licence, visit http://creativecommons.org/licenses/by/4.0/.

\section{References}

1. Silvestri E, Barile A, Albano D et al (2018) Interventional therapeutic procedures in the musculoskeletal system: an Italian Survey by the Italian College of Musculoskeletal Radiology. Radiol Med 123:314-321. https://doi.org/10.1007/s11547-017-0842-7

2. Soneji N, Peng PWH (2016) Ultrasound-guided interventional procedures in pain medicine: a review of anatomy, sonoanatomy, and procedures: Part VI: Ankle Joint. Reg Anesth Pain Med 41:99-116. https://doi.org/10.1097/AAP.0000000000000344

3. Hansford BG, Mills MK, Hanrahan CJ, Yablon CM (2019) Pearls and pitfalls of fluoroscopic-guided foot and ankle injections: what the radiologist needs to know. Skelet Radiol 48:1661-1674. https:// doi.org/10.1007/s00256-019-03226-9

4. Albano D, Chianca V, Tormenta S et al (2017) Old and new evidence concerning the crucial role of ultrasound in guiding intraarticular injections. Skelet Radiol 46:963-964. https://doi.org/10. 1007/s00256-017-2644-3

5. Albano D, Vicentin I, Messina C, Sconfienza LM (2020) Postsurgical Achilles calcific tendinopathy treated with ultrasoundguided percutaneous irrigation. Skelet Radiol 49:1475-1480. https://doi.org/10.1007/s00256-020-03453-5

6. Walter WR, Burke CJ, Adler RS (2017) Ultrasound-guided therapeutic injections for neural pathology about the foot and ankle: a 4 year retrospective review. Skelet Radiol 46:795-803. https://doi. org/10.1007/s00256-017-2624-7 
7. Albano D, Aringhieri G, Messina C et al (2020) High-frequency and ultra-high frequency ultrasound: musculoskeletal imaging up to $70 \mathrm{MHz}$. Semin Musculoskelet Radiol 24:125-134. https://doi.org/ $10.1055 / \mathrm{s}-0039-3401042$

8. Yablon C (2013) Ultrasound-guided interventions of the foot and ankle. Semin Musculoskelet Radiol 17:60-68. https://doi.org/10. 1055/s-0033-1333916

9. Sofka CM, Adler RS (2002) Ultrasound-guided interventions in the foot and ankle. Semin Musculoskelet Radiol 6:163-168. https://doi. org/10.1055/s-2002-32362

10. Hohmann E, Tetsworth K, Glatt V (2020) Platelet-rich plasma versus corticosteroids for the treatment of plantar fasciitis: a systematic review and meta-analysis. Am J Sports Med. https://doi.org/10. $1177 / 0363546520937293$

11. Krogh TP, Ellingsen T, Christensen R et al (2016) Ultrasoundguided injection therapy of Achilles tendinopathy with plateletrich plasma or saline. Am J Sports Med 44:1990-1997. https:// doi.org/10.1177/0363546516647958

12. Cazzato RL, Garnon J, Ramamurthy N et al (2016) Percutaneous MR-guided cryoablation of Morton's neuroma: rationale and technical details after the first 20 patients. Cardiovasc Intervent Radiol 39:1491-1498. https://doi.org/10.1007/s00270-016-1365-7

13. Sconfienza LM, Adriaensen M, Albano D et al (2020) Clinical indications for image guided interventional procedures in the musculoskeletal system: a Delphi-based consensus paper from the European Society of Musculoskeletal Radiology (ESSR) - part III, nerves of the upper limb. Eur Radiol 30:1498-1506. https:// doi.org/10.1007/s00330-019-06479-z

14. Sconfienza LM, Albano D, Allen G et al (2018) Clinical indications for musculoskeletal ultrasound updated in 2017 by European Society of Musculoskeletal Radiology (ESSR) consensus. Eur Radiol. https://doi.org/10.1007/s00330-018-5474-3

15. Sconfienza LM, Adriaensen M, Albano D et al (2020) Clinical indications for image-guided interventional procedures in the musculoskeletal system: a Delphi-based consensus paper from the European Society of Musculoskeletal Radiology (ESSR) - part I, shoulder. Eur Radiol 30: 903-913. https://doi.org/10.1007/s00330-019-06419-x

16. Sconfienza LM, Adriaensen M, Albano D et al (2020) Clinical indications for image-guided interventional procedures in the musculoskeletal system: a Delphi-based consensus paper from the European Society of Musculoskeletal Radiology (ESSR)-Part II, elbow and wrist. Eur Radiol 30:2220-2230. https://doi.org/10. 1007/s00330-019-06545-6

17. Steurer J (2011) The Delphi method: an efficient procedure to generate knowledge. Skelet Radiol 40:959-961. https://doi.org/10. 1007/s00256-011-1145-Z

18. Messina C, Vitale JA, Pedone L et al (2020) Critical appraisal of papers reporting recommendation on sarcopenia using the AGREE II tool: a EuroAIM initiative. Eur J Clin Nutr 74:1164-1172. https:// doi.org/10.1038/s41430-020-0638-z

19. Kearney RS, Parsons N, Metcalfe D, Costa ML (2015) Injection therapies for Achilles tendinopathy. Cochrane Database Syst Rev. https://doi.org/10.1002/14651858.CD010960.pub2

20. Maffulli N, Papalia R, D'Adamio S et al (2015) Pharmacological interventions for the treatment of Achilles tendinopathy: a systematic review of randomized controlled trials. Br Med Bull 113:101115. https://doi.org/10.1093/bmb/ldu040

21. Lin MT, Chiang CF, Wu CH et al (2018) Meta-analysis comparing autologous blood-derived products (including platelet-rich plasma) injection versus placebo in patients with Achilles tendinopathy. Arthrosc J Arthrosc Relat Surg 34:1966-1975.e5. https://doi.org/ 10.1016/j.arthro.2018.01.030

22. Zhang YJ, Xu SZ, Gu PC et al (2018) Is platelet-rich plasma injection effective for chronic Achilles tendinopathy? A meta-analysis. Clin Orthop Relat Res 476:1633-1641. https://doi.org/10.1007/ s11999.0000000000000258
23. De Vos RJ, Weir A, Van Schie HTM et al (2010) Platelet-rich plasma injection for chronic Achilles tendinopathy: a randomized controlled trial. J Am Med Assoc 303:144-149. https://doi.org/10. 1001/jama.2009.1986

24. De Jonge S, De Vos RJ, Weir A et al (2011) One-year follow-up of platelet-rich plasma treatment in chronic achilles tendinopathy: a double-blind randomized placebo-controlled trial. Am J Sports Med 39:1623-1629. https://doi.org/10.1177/0363546511404877

25. Nauwelaers AK, Van Oost L, Peers K (2020) Evidence for the use of PRP in chronic midsubstance Achilles tendinopathy: a systematic review with meta-analysis. Foot Ankle Surg. https://doi.org/10. 1016/j.fas.2020.07.009

26. Abate M, Di Carlo L, Salini V (2019) Platelet rich plasma compared to dry needling in the treatment of non-insertional Achilles tendinopathy. Phys Sportsmed 47:232-237. https://doi.org/10. 1080/00913847.2018.1548886

27. Metcalfe D, Achten J, Costa ML (2009) Glucocorticoid injections in lesions of the Achilles tendon. Foot Ankle Int 30:661-665. https://doi.org/10.3113/FAI.2009.0661

28. Drakonaki EE, Allen GM, Watura R (2016) Ultrasound-guided intervention in the ankle and foot. Br J Radiol. https://doi.org/10. 1259/bjr.20150577

29. Coombes BK, Bisset L, Vicenzino B (2010) Efficacy and safety of corticosteroid injections and other injections for management of tendinopathy: a systematic review of randomised controlled trials. Lancet 376:1751-1767. https://doi.org/10.1016/S0140-6736(10) 61160-9

30. Usuelli FG, Grassi M, Maccario C et al (2018) Intratendinous adipose-derived stromal vascular fraction (SVF) injection provides a safe, efficacious treatment for Achilles tendinopathy: results of a randomized controlled clinical trial at a 6-month follow-up Knee Surgery. Sport Traumatol Arthrosc 26:2000-2010. https://doi.org/ 10.1007/s00167-017-4479-9

31. Albano D, Messina C, Usuelli FG, et al (2017) Magnetic resonance and ultrasound in achilles tendinopathy: predictive role and response assessment to platelet-rich plasma and adipose-derived stromal vascular fraction injection. Eur J Radiol. https://doi.org/10. 1016/j.ejrad.2017.08.006

32. Morath O, Kubosch EJ, Taeymans J et al (2018) The effect of sclerotherapy and prolotherapy on chronic painful Achilles tendinopathy - a systematic review including meta-analysis. Scand J Med Sci Sports 28: 4-15. https://doi.org/10.1111/sms. 12898

33. Ebbesen BH, Mølgaard CM, Olesen JL et al (2018) No beneficial effect of Polidocanol treatment in Achilles tendinopathy: a randomised controlled trial. Knee Surgery, Sport Traumatol Arthrosc 26:2038 2044. https://doi.org/10.1007/s00167-017-4675-7

34. Boesen AP, Hansen R, Boesen MI et al (2017) Effect of highvolume injection, platelet-rich plasma, and sham treatment in chronic midportion achilles tendinopathy: a randomized doubleblinded prospective study. Am J Sports Med 45:2034-2043. https://doi.org/10.1177/0363546517702862

35. Boesen AP, Langberg H, Hansen R et al (2019) High volume injection with and without corticosteroid in chronic midportion achilles tendinopathy. Scand J Med Sci Sports 29:1223-1231. https:// doi.org/10.1111/sms. 13450

36. Jaffee NW, Gilula LA, Wissman RD, Johnson JE (2001) Diagnostic and therapeutic ankle: outcomes and complications. AJR Am J Roentgenol 176:365-371. https://doi.org/10.2214/ajr.176.2.1760365

37. Cooper AJ, Mizel MS, Patel PD et al (2007) Comparison of MRI and local anesthetic tendon sheath injection in the diagnosis of posterior tibial tendon tenosynovitis. Foot Ankle Int 28:11241127. https://doi.org/10.3113/FAI.2007.1124

38. Peters SE, Laxer RM, Connolly BL, Parra DA (2017) Ultrasoundguided steroid tendon sheath injections in juvenile idiopathic arthritis: a 10-year single-center retrospective study. Pediatr Rheumatol. https://doi.org/10.1186/s12969-017-0155-3 
39. Laurell L, Court-Payen M, Nielsen S, et al (2011) Ultrasonography and color Doppler in juvenile idiopathic arthritis: diagnosis and follow-up of ultrasound-guided steroid injection in the ankle region. A descriptive interventional study. Pediatr Rheumatol. https://doi. org/10.1186/1546-0096-9-4

40. Brophy DP, Cunnane G, Fitzgerald O, Gibney RG (1995) Technical report: ultrasound guidance for injection of soft tissue lesions around the heel in chronic inflammatory arthritis. Clin Radiol 50:120-122. https://doi.org/10.1016/S0009-9260(05)82995-2

41. Li Z, Xia C, Yu A, Qi B (2014) Ultrasound- versus palpationguided injection of corticosteroid for plantar fasciitis: a meta-analysis. PLoS One. https://doi.org/10.1371/journal.pone.0092671

42. Chen CM, Chen JS, Tsai WC et al (2013) Effectiveness of deviceassisted ultrasound-guided steroid injection for treating plantar fasciitis. Am J Phys Med Rehabil 92:597-605. https://doi.org/10. 1097/PHM.0b013e318278a831

43. Ball EMA, McKeeman HMA, Patterson C et al (2013) Steroid injection for inferior heel pain: a randomised controlled trial. Ann Rheum Dis 72:996-1002. https://doi.org/10.1136/annrheumdis-2012-201508

44. Schulhofer SD (2013) Short-term benefits of ultrasound-guided corticosteroid injection in plantar fasciitis. Clin J Sport Med 23: 83-84. https://doi.org/10.1097/JSM.0b013e31827e9ec9

45. Kayhan A, Gökay NS, Alpaslan R et al (2011) Sonographically guided corticosteroid injection for treatment of plantar fasciosis. $\mathrm{J}$ Ultrasound Med 30:509-515. https://doi.org/10.7863/jum.2011.30. 4.509

46. Tsai WC, Wang CL, Tang FT et al (2000) Treatment of proximal plantar fasciitis with ultrasound-guided steroid injection. Arch Phys Med Rehabil 81:1416-1421. https://doi.org/10.1053/apmr.2000.9175

47. Ryan MB, Wong AD, Gillies JH et al (2009) Sonographically guided intratendinous injections of hyperosmolar dextrose/lidocaine: a pilot study for the treatment of chronic plantar fasciitis. Br J Sports Med 43:303-306. https://doi.org/10.1136/bjsm.2008.050021

48. Johannsen FE, Herzog RB, Malmgaard-Clausen NM et al (2019) Corticosteroid injection is the best treatment in plantar fasciitis if combined with controlled training. Knee Surgery, Sport Traumatol Arthrosc 27:5-12. https://doi.org/10.1007/s00167-018-5234-6

49. Alkhatib N, Salameh M, Ahmed AF et al (2020) Platelet-rich plasma versus corticosteroids in the treatment of chronic plantar fasciitis: a systematic review and meta-analysis of prospective comparative studies. J Foot Ankle Surg 59:546-552. https://doi.org/10. 1053/j.jfas.2019.10.003

50. Mohammed W, Farah S, Nassiri M, McKenna J (2020) Therapeutic efficacy of platelet-rich plasma injection compared to corticosteroid injection in plantar fasciitis: a systematic review and meta-analysis. J Orthop 22:124-134. https://doi.org/10.1016/j.jor.2020.03.053

51. Hurley ET, Shimozono Y, Hannon CP et al (2020) Platelet-rich plasma versus corticosteroids for plantar fasciitis: a systematic review of randomized controlled trials. Orthop J Sport Med. https:// doi.org/10.1177/2325967120915704

52. Huang YC, Wei SH, Wang HK, Lieu FK (2010) Ultrasonographic guided botulinum toxin type a for plantar fasciitis: an outcomebased investigation for treating pain and gait changes. J Rehabil Med 42:136-140. https://doi.org/10.2340/16501977-0491

53. Babaei-Ghazani A, Karimi N, Forogh B et al (2019) Comparison of ultrasound-guided local ozone (O2-O3) injection vs corticosteroid injection in the treatment of chronic plantar fasciitis: a randomized clinical trial. Pain Med 20:314-322. https://doi.org/10.1093/pm/ pny066

54. Kumai T, Samoto N, Hasegawa A et al (2018) Short-term efficacy and safety of hyaluronic acid injection for plantar fasciopathy Knee Surgery. Sport Traumatol Arthrosc 26:903-911. https://doi.org/10. 1007/s00167-017-4467-0

55. Khosla S, Thiele R, Baumhauer JF (2009) Ultrasound guidance for intra-articular injections of the foot and ankle. Foot Ankle Int 30: 886-890. https://doi.org/10.3113/FAI.2009.0886
56. Kirk KL, Campbell JT, Guyton GP, Schon LC (2008) Accuracy of posterior subtalar joint injection without fluoroscopy. Clin Orthop Relat Res 466:2856-2860. https://doi.org/10.1007/s11999-008-0236-1

57. Jha AJ, Viner GC, McKissack H et al (2020) Accuracy of talonavicular injection using ultrasound versus anatomical landmark: a cadaver study. Acta Radiol 61:1359-1364. https://doi. org/10.1177/0284185120901507

58. Remedios D, Martin K, Kaplan G et al (1997) Juvenile chronic arthritis: diagnosis and management of tibio-talar and sub-talar disease. Br J Rheumatol 36:1214-1217. https://doi.org/10.1093/ rheumatology/36.11.1214

59. Protheroe D, Gadgil A (2018) Guided intra-articular corticosteroid injections in the midfoot. Foot Ankle Int 39:1001-1004. https://doi. org/10.1177/1071100718779983

60. Drakonaki EE, Kho JSB, Sharp RJ, Ostlere SJ (2011) Efficacy of ultrasound-guided steroid injections for pain management of midfoot joint degenerative disease. Skelet Radiol 40:1001-1006. https://doi.org/10.1007/s00256-010-1094-y

61. Akpancar S, Gül D (2019) Comparison of platelet rich plasma and prolotherapy in the management of osteochondral lesions of the talus: a retrospective cohort study. Med Sci Monit 25:5640-5647. https://doi.org/10.12659/MSM.914111

62. Cooper AJ, Clifford PD, Parikh VK et al (2009) Instability of the first metatarsal-cuneiform joint: diagnosis and discussion of an independent pain generator in the foot. Foot Ankle Int 30:928-932. https://doi.org/10.3113/FAI.2009.0928

63. Mitchell MJ, Bielecki D, Bergman AG et al (1995) Localization of specific joint causing hindfoot pain: value of injecting local anesthetics into individual joints during arthrography. AJR Am J Roentgenol 164:1473-1476. https://doi.org/10.2214/ajr.164.6. 7754895

64. Stegeman M, Van Ginneken BTJ, Boetes B, et al (2014) Can diagnostic injections predict the outcome in foot and ankle arthrodesis? BMC Musculoskelet Disord. https://doi.org/10.1186/1471-2474-15-11

65. Khoury NJ, El-Khoury GY, Saltzman CL, Brandser EA (1996) Intraarticular foot and ankle injections to identify source of pain before arthrodesis. AJR Am J Roentgenol 167:669-673. https:// doi.org/10.2214/ajr.167.3.8751679

66. Newman JS (2004) Diagnostic and therapeutic injections of the foot and ankle. Semin Roentgenol 39:85-94. https://doi.org/10.1016/j. ro.2003.10.008

67. Fernández-Gibello A, Moroni S, Camuñas G et al (2019) Ultrasound-guided decompression surgery of the tarsal tunnel: a novel technique for the proximal tarsal tunnel syndrome-Part II. Surg Radiol Anat 41:43-51

68. Chiodo CP, Logan C, Blauwet CA (2018) Aspiration and injection techniques of the lower extremity. J Am Acad Orthop Surg 26: e313-e320. https://doi.org/10.5435/JAAOS-D-16-00762

69. Hassouna H, Singh D, Taylor H, Johnson S (2007) Ultrasound guided steroid injection in the treatment of interdigital neuralgia. Acta Orthop Belg 73:224-229

70. Chianca V, Orlandi D, Messina C, et al (2019) Interventional therapeutic procedures to treat degenerative and inflammatory musculoskeletal conditions: state of the art. Radiol Medica. https://doi.org/ 10.1007/s11547-019-01018-8

71. Goldberg-Stein S, Berko N, Thornhill B et al (2016) Fluoroscopically guided retrocalcaneal bursa steroid injection: description of the technique and pilot study of short-term patient outcomes. Skelet Radiol 45:1107-1112. https://doi.org/10.1007/ s00256-016-2368-9

72. Srivastava P, Aggarwal A (2016) Ultrasound-guided retro-calcaneal bursa corticosteroid injection for refractory Achilles tendinitis in patients with seronegative spondyloarthropathy: efficacy and follow-up study. Rheumatol Int 36:875-880. https://doi.org/10. 1007/s00296-016-3440-4 
73. Turmo-Garuz A, Rodas G, Balius R et al (2014) Can local corticosteroid injection in the retrocalcaneal bursa lead to rupture of the Achilles tendon and the medial head of the gastrocnemius muscle? Musculoskelet Surg 98:121-126. https://doi.org/10.1007/s12306013-0305-9

74. Matthews BG, Hurn SE, Harding MP et al (2019) The effectiveness of non-surgical interventions for common plantar digital compressive neuropathy (Morton's neuroma): a systematic review and meta-analysis. J Foot Ankle Res. https://doi.org/10.1186/s13047-019-0320-7

75. Thomson CE, Beggs I, Martin DJ et al (2013) Methylprednisolone injections for the treatment of morton neuroma: a patient-blinded randomized trial. J Bone Jt Surg Am 95:790-798. https://doi.org/ 10.2106/JBJS.I.01780

76. Lizano-Díez X, Ginés-Cespedosa A, Alentorn-Geli E et al (2017) Corticosteroid injection for the treatment of Morton's neuroma: a prospective, double-blinded, randomized, placebo-controlled trial. Foot Ankle Int 38:944-951. https://doi.org/10.1177/ 1071100717709569

77. Morgan P, Monaghan W, Richards S (2014) A systematic review of ultrasound-guided and non-ultrasound-guided therapeutic injections to treat Morton's neuroma. J Am Podiatr Med Assoc 104: 337-348. https://doi.org/10.7547/0003-0538-104.4.337

78. Ruiz Santiago F, Prados Olleta N, Tomás Muñoz P et al (2019) Short term comparison between blind and ultrasound guided injection in Morton neuroma. Eur Radiol 29:620-627. https://doi.org/10. 1007/s00330-018-5670-1

79. Saygi B, Yildirim Y, Saygi EK et al (2005) Morton neuroma: comparative results of two conservative methods. Foot Ankle Int 26: 556-559. https://doi.org/10.1177/107110070502600711

80. Markovic M, Crichton K, Read JW et al (2008) Effectiveness of ultrasound-guided corticosteroid injection in the treatment of Morton's neuroma. Foot Ankle Int 29:483-487. https://doi.org/10. 3113/fai-2008-0483

81. Park YH, Lee JW, Choi GW, Kim HJ (2018) Risk factors and the associated cutoff values for failure of corticosteroid injection in treatment of Morton's neuroma. Int Orthop 42:323-329. https:// doi.org/10.1007/s00264-017-3707-8

82. Hughes RJ, Ali K, Jones H et al (2007) Treatment of Morton's neuroma with alcohol injection under sonographic guidance: Follow-up of 101 cases. AJR Am J Roentgenol 188:1535-1539. https://doi.org/10.2214/AJR.06.1463

83. Musson RE, Sawhney JS, Lamb L et al (2012) Ultrasound guided alcohol ablation of Morton's neuroma. Foot Ankle Int 33:196-201. https://doi.org/10.3113/FAI.2012.0196

84. Gurdezi S, White T, Ramesh P (2013) Alcohol injection for Morton's neuroma: a five-year follow-up. Foot Ankle Int 34: 1064-1067. https://doi.org/10.1177/1071100713489555

85. Pasquali C, Vulcano E, Novario R et al (2015) Ultrasound-guided alcohol injection for Morton's neuroma. Foot Ankle Int 36:55-59. https://doi.org/10.1177/1071100714551386
86. Perini L, Perini C, Tagliapietra M et al (2016) Percutaneous alcohol injection under sonographic guidance in Morton's neuroma: follow-up in 220 treated lesions. Radiol Med 121:597-604. https://doi.org/10.1007/s11547-016-0622-9

87. Lorenzon P, Rettore C (2018) Mechanical metatarsalgia as a risk factor for relapse of Morton's neuroma after ultrasound-guided alcohol injection. J Foot Ankle Surg 57:870-875. https://doi.org/10. 1053/j.jfas.2018.03.003

88. Santos D, Morrison G, Coda A (2018) Sclerosing alcohol injections for the management of intermetatarsal neuromas: a systematic review. Foot 35:36-47. https://doi.org/10.1016/j.foot.2017.12.003

89. Chuter GSJ, Chua YP, Connell DA, Blackney MC (2013) Ultrasound-guided radiofrequency ablation in the management of interdigital (Morton's) neuroma. Skelet Radiol 42:107-111. https:// doi.org/10.1007/s00256-012-1527-x

90. Masala S, Cuzzolino A, Morini M et al (2018) Ultrasound-guided percutaneous radiofrequency for the treatment of Morton's neuroma. Cardiovasc Intervent Radiol 41:137-144. https://doi.org/10. 1007/s00270-017-1786-y

91. Shah R, Ahmad M, Hanu-Cernat D, Choudhary S (2019) Ultrasound-guided radiofrequency ablation for treatment of Morton's neuroma: initial experience. Clin Radiol 74:815.e9815.e13. https://doi.org/10.1016/j.crad.2019.07.002

92. Lee K, Hwang IY, Ryu CH et al (2018) Ultrasound-guided hyaluronic acid injection for the management of Morton's neuroma. Foot Ankle Int 39:201-204. https://doi.org/10.1177/ 1071100717739578

93. Yap LP, Mcnally E (2012) Patient's assessment of discomfort during ultrasound-guided injection of Morton's neuroma: Selecting the optimal approach. J Clin Ultrasound 40:330-334. https://oi.org/ $10.1002 /$ jcu. 21926

94. Mahadevan D, Salmasi M, Whybra N et al (2016) What factors predict the need for further intervention following corticosteroid injection of Morton's neuroma? Foot Ankle Surg 22:9-11. https:// doi.org/10.1016/j.fas.2015.03.007

95. Makki D, Haddad BZ, Mahmood Z et al (2012) Efficacy of corticosteroid injection versus size of plantar interdigital neuroma. Foot Ankle Int 33:722-726. https://doi.org/10.3113/FAI.2012.0722

96. Pabinger C, Malaj I, Lothaller $\mathrm{H}$ et al (2020) Improved injection technique of ethanol for Morton's neuroma. Foot Ankle Int 41:590 595. https://doi.org/10.1177/1071100720903096

97. Friedman T, Richman D, Adler R (2012) Sonographically guided cryoneurolysis preliminary experience and clinical outcomes. J Ultrasound Med 31:2025-2034. https://doi.org/10.7863/jum.2012. 31.12.2025

Publisher's note Springer Nature remains neutral with regard to jurisdictional claims in published maps and institutional affiliations.

\section{Affiliations}

Luca Maria Sconfienza $^{1,2}$ (1) $\cdot$ Miraude Adriaensen ${ }^{3} \cdot$ Domenico Albano $^{1,4} \cdot$ Andrea Alcala-Galiano $^{5} \cdot$ Georgina Allen $^{6,7}$. Maria Pilar Aparisi Gómez ${ }^{8,9} \cdot$ Giacomo Aringhieri $^{10}$. Alberto Bazzocchi ${ }^{11} \cdot$ lan Beggs ${ }^{12}$. Vito Chianca ${ }^{13,14}$. Angelo Corazza ${ }^{1}$. Danoob Dalili ${ }^{15}$. Miriam De Dea ${ }^{16}$. Jose Luis del Cura ${ }^{17}$. Francesco Di Pietto ${ }^{18} \cdot$ Elena Drakonaki $^{19}$. Fernando Facal de Castro ${ }^{20}$. Dimitrios Filippiadis ${ }^{21}$. Salvatore Gitto ${ }^{22}$. Andrew J Grainger ${ }^{23}$ - Simon Greenwood ${ }^{24}$. Harun Gupta ${ }^{25}$ - Amanda Isaac ${ }^{15,26}$. Slavcho Ivanoski ${ }^{27,28}$ • Monica Khanna ${ }^{29}$. Andrea Klauser ${ }^{30}$ - Ramy Mansour ${ }^{31}$. Silvia Martin ${ }^{32}$. Vasco Mascarenhas $s^{33,34}$. Giovanni Mauri ${ }^{35,36}$. Catherine McCarthy ${ }^{37}$. David McKean ${ }^{38}$. Eugene McNally ${ }^{37}$ - Kalliopi Melaki ${ }^{39}$ - Carmelo Messina ${ }^{1} \cdot$ Rebeca Mirón Mombiela ${ }^{40}$ - Ricardo Moutinho ${ }^{33,41}$. Cyprian Olchowy ${ }^{42}$. Davide Orlandi ${ }^{43}$. Raquel Prada González ${ }^{44}$. Mahesh Prakash ${ }^{45}$. Magdalena Posadzy ${ }^{46}$. Saulius Rutkauskas ${ }^{47} \cdot$ Žiga Snoj ${ }^{48,49}$. Alberto Stefano Tagliafico ${ }^{50,51}$ - Alexander Talaska ${ }^{52} \cdot$ Xavier Tomas $^{53}$. 
Violeta Vasilevska Nikodinovska ${ }^{54,55}$. Jelena Vucetic ${ }^{56} \cdot$ David Wilson $^{6}$ • Federico Zaottini ${ }^{51}$ - Marcello Zappia ${ }^{57,58}$. Marina Obradov 59

1 Unit of Diagnostic and Interventional Radiology, IRCCS Istituto Ortopedico Galeazzi, Via Riccardo Galeazzi 4, 20161 Milan, Italy

2 Dipartimento di Scienze Biomediche per la Salute, Università degli Studi di Milano, Milan, Italy

3 Department of Medical Imaging, Zuyderland Medical Center, Sittard-Geleen, Heerlen, Brunssum, Kerkrade, the Netherlands

4 Sezione di Scienze Radiologiche, Dipartimento di Biomedicina, Neuroscienze e Diagnostica Avanzata, Università degli Studi di Palermo, Palermo, Italy

5 Hospital Universitario 12 de Octubre, Madrid, Spain

6 St Luke's Radiology Oxford Ltd, Oxford, UK

7 University of Oxford, Oxford, UK

8 Department of Radiology, Auckland City Hospital, Auckland, New Zealand

9 Department of Radiology, Hospital Vithas Nueve de Octubre, Valencia, Spain

10 Diagnostic and Interventional Radiology, Department of Translational Research and New Technologies in Medicine and Surgery, University of Pisa, Pisa, Italy

11 Diagnostic and Interventional Radiology, IRCCS Istituto Ortopedico Rizzoli, Bologna, Italy

12 Analytic Imaging, Edinburgh, UK

13 Ospedale Evangelico Betania, Napoli, Italy

14 Clinica di Radiologia EOC IIMSI, Lugano, Switzerland

15 School of Biomedical Engineering \& Imaging Sciences, King's College London, London, UK

16 Studio MSK, Belluno, Italy

17 Hospital Universitario Donostia, San Sebastian, Spain

18 Dipartimento di Diagnostica per Immagini, Pineta Grande Hospital, Castel Volturno, Italy

19 MSK Radiology Services, Heraklion, Crete, Greece

20 Hospital General Universitario de Valencia, Valencia, Spain

21 2nd Department of Radiology, University General Hospital "ATTIKON" Medical School, National and Kapodistrian University of Athens, Haidari, Athens, Greece

22 Dipartimento di Scienze Biomediche per la Salute, Università degli Studi di Milano, Milan, Italy

23 Cambridge University Hospitals, Cambridge, UK

24 Mid Cheshire Hospitals NHS Foundation Trust, Cheshire, UK

25 Leeds Teaching Hospitals, Leeds, UK

26 Guy's and St Thomas' Hospitals, London, UK
27 Department of Radiology, Special Hospital for Orthopedic Surgery and Traumatology, St. Erazmo -, Ohrid, North Macedonia

28 Ss. Cyril and Methodius University of Skopje, Skopje, North Macedonia

29 Imperial College Healthcare NHS Trust, London, UK

30 Department of Radiology, Medical University Innsbruck, Innsbruck, Austria

31 Oxford Musculoskeletal Radiology, Oxford University Hospitals, Oxford, UK

32 Hospital Universitario Son Llatzer, Palma, Spain

33 Hospital da Luz, Musculoskeletal Imaging Unit, Lisbon, Portugal

34 AIRC, Advanced Imaging Research Consortium, Lisbon, Portugal

35 Division of Interventional Radiology, Istituto Europeo di Oncologia, Milan, Italy

36 Department of Oncology and Hemato-Oncology, University of Milano, Milan, Italy

37 Oxford Musculoskeletal Radiology, Oxford, UK

38 Buckinghamshire Healthcare NHS Trust, Aylesbury, UK

39 Department of Radiology, Charité-Universitätsmedizin Berlin, Berlin, Germany

40 Department of Radiology, Herlev Gentofte Hospital, Herlev, Denmark

41 Hospital de Loulé, Loulé, Portugal

42 Department of Oral Surgery, Wroclaw Medical University, Wroclaw, Poland

43 Department of Radiology, Ospedale Evangelico Internazionale, Genoa, Italy

44 Ribera Povisa Hospital, Vigo, Spain

45 Post Graduate Institute of Medical Education \& Research (PGIMER), Chandigarh, India

46 Indywidualna Praktyka Lekarska Magdalena Posadzy, Poznan, Poland

47 Department of Radiology, Lithuanian University of Health Sciences, Kaunas, Lithuania

48 Institute of Radiology, University Medical Centre Ljubljana, Zaloska 7, 1000 Ljubljana, Slovenia

49 Faculty of Medicine, University of Ljubljana, Ljubljana, Slovenia

50 Department of Health Sciences, University of Genova, Genoa, Italy

51 IRCCS Ospedale Policlinico San Martino, Genova, Italy

52 Department of Radiology, AUVA Trauma Center Vienna, Vienna, Austria 
53 Radiology Dpt. MSK Unit. Hospital Clinic (CDIC), University of Barcelona (UB), Barcelona, Spain

54 University Institute of Radiology, Skopje, Macedonia

55 Ss. Cyril and Methodius University in Skopje, Skopje, Macedonia

56 Radiology Department, Hospital ICOT Ciudad de Telde, Las

Palmas, Spain
57 Department of Medicine and Health Sciences, University of Molise, Campobasso, Italy

58 Varelli Institute, Naples, Italy

59 Department of Radiology, Sint Maartenskliniek, Nijmegen, The Netherlands 